\title{
Electronic Structure and Dipole Moment Calculations of the Electronic States of the Molecule ZnS
}

\author{
Abeer Youssef ${ }^{1}$, Ghassan Younes $^{1} \&$ Mahmoud Korek $^{1}$ \\ ${ }^{1}$ Faculty of Science, Beirut Arab University, Lebanon \\ Correspondence: Mahmoud Korek, Faculty of science, Beirut Arab University, P.O.Box 11-5020, Beirut Lebanon. \\ E-mail: mahmoud.korek@bau.edu.lb, fkorek@yahoo.com
}

Received: September 12, 2017

Accepted: October 30, $2017 \quad$ Online Published: February 28, 2018

doi:10.5539/mas.v12n3p132

URL: https://doi.org/10.5539/mas.v12n3p132

\begin{abstract}
In this study, the low lying electronic states and spectroscopy of diatomic molecule $\mathrm{ZnS}$ in addition to its dipole moments have been investigated by performing highly correlated ab initio calculations, the Complete Active Space Self Consistent Field (CASSCF) method with Multi Reference Configuration Interaction (MRCI+Q) for an accurate picture for these states. The proposed study includes information about the potential energy curves of the lowest 12 singlet and 9 triplet electronic states of the molecule $\mathrm{ZnS}$, in the representation ${ }^{2 \mathrm{~s}^{+}} \Lambda^{(+/)}$. Nine of these states have been studied here for the first time. The harmonic frequency $w_{e}$, the internuclear distance $r_{e}$, the electronic energy with respect to the ground state $T_{e}$, the rotational constant $B_{e}$, and the permanent dipole moment $\mu$ have been calculated, compared and compiled with the available existing data to illustrate the electronic characteristics. The comparison of these values reveals a very good agreement.
\end{abstract}

Keywords: ab initio calculation, electronic structure, spectroscopic constants, potential energy curves, dipole moments

\section{Introduction}

The zinc Chalcogenides ( $\mathrm{ZnS}, \mathrm{ZnSe}$, and $\mathrm{ZnTe}$ ) are diatomic molecules yield from the combination between a metal of group $\mathrm{IIb}(\mathrm{Zn}, \mathrm{Cd}, \mathrm{Hg})$ with a valence electronic configuration $\mathrm{ns}^{2}$ and a chalcogen $(\mathrm{O}, \mathrm{S}, \mathrm{Se}, \mathrm{Te})$ with a valence electronic configuration n's ${ }^{2} n^{\prime} p^{4}$ (Chamboud 2008). These compounds have the wide band gap, the high iconicity $(0.77,0.63$, and 0.49 respectively) of chemical bond, the smaller energy of formation of vacancies, and they are very sensitive to any strain (Peterson, Spheler, Singleton, 2007).

These compounds are the promising materials for their use in many optoelectronic applications. The zinc sulphide $\mathrm{ZnS}$ exists both in natural and synthetic crystalline form possessing cubic or hexagonal structures. The poly-nuclear diatomic molecule $\mathrm{ZnS}$ is used in luminescent materials such as X-ray screens to glow in the dark products. With copper this molecule is used in electroluminescent panels and also exhibit phosphorescence. $\mathrm{ZnS}$ is used also for infrared optical materials such as optical window or shaped into lenses, pigment which with barium sulfate forms lithopone used for interior paints and a pigment used to change color of reflected or transmitted ray. Also it is commonly used as a source of evaporation and as a semiconductor for electronic and solar applications. Away from lab, $\mathrm{ZnS}$ is usually produced from waste materials such as cosmetic, pharmaceutical, and rubber industries. Thus, they perform a toxicity and harmful impact on aquatic life as disturbing the dissolved oxygen content of the water (Wikipedia).

The aim of this study is to calculate the near-equilibrium potential energy of the lowest electronic states of diatomic molecule zinc sulfide $\mathrm{ZnS} .{ }^{1} \mathrm{~S}^{+}$and ${ }^{3} \mathrm{P}$ are the ground and the first exited states respectively. The ${ }^{1} \mathrm{~S}^{+}$ $\left(1 \mathrm{~s}^{2}, 1 \mathrm{~d}^{4}, 1 \mathrm{p}^{4}, 2 \mathrm{~s}^{2}, 3 \mathrm{~s}^{2}, 2 \mathrm{p}^{4}, 4 \mathrm{~s}^{0}\right)$ is known always as shorter equilibrium band energy dissociation and larger dipole moment compared to those of ${ }^{3} \mathrm{P}\left(1 \mathrm{~s}^{2}, 1 \mathrm{~d}^{4}, 1 \mathrm{p} 4,2 \mathrm{~s}^{2}, 3 \mathrm{~s}^{2}, 2 \mathrm{p}^{3}, 4 \mathrm{~s}^{1}\right)$ where state ${ }^{1} \mathrm{~S}^{+}$is stabilized relative to ${ }^{3} \mathrm{P}$. Because of these properties, any small change in the bond length leads to a great change in the electronic structure without involving a large quantity of energy (Chamboud 2008).

\section{Method}

The given study is based on configuration interaction (CI) and on Multi-Reference configuration interaction methods (MRCI) where the CI calculation includes instantaneous electron correlation. It is also called as configuration mixing method (CM) where it involves first-higher order corrections to the Hartree-Fock wave 
function. It is useful for calculating excited states of molecules, where the Hartree-Fock fails (Atkins \& Friedman).

In the present work, the low-lying singlet, and triplet electronic states of the molecule $\mathrm{ZnS}$ are calculated using Complete Active Space Self Consistent Field (CASSCF) procedure followed by a multireference configuration interaction (MRCI+Q with Davidson correction) treatment for the electron correlation. The entire CASSCF configuration space was done by the means of the computational chemistry program MOLPRO (MOLPRO) taking advantage of the graphical user interface GABEDIT (Allouche 2011).

The 30 electrons of zinc atom and the 16 electrons of sulfur atom are taken as a system relative to ECP10MDF as basis set for $s, p$, and $d$ orbitals, and ECP10MWB basis z-set for $s$ and $p$ orbitals with $d$ orbital which is treated by aug-cc-PVDZ basis set respectively. Therefore, the diatomic molecule is studied as 26 free electrons among 12 electrons were frozen and 14 as valance electrons corresponding to active orbitals were explicitly treated with 10 valance orbitals.

\section{Results}

\subsection{Potential Energy Curves and Spectroscopic Constants}

The potential energy curves (PECs) for the 21 singlet, and triplet electronic states, in the representation ${ }^{2 \mathrm{~s}+1} \Lambda^{(+/)}$, of the molecule $\mathrm{ZnS}$ were performed using the MRCI+Q for internuclear distances calculations in the range $1.4 \hat{\AA} \leq \mathrm{R}_{\mathrm{e}} \leq 4.4 \hat{\AA}$ (figs. (1-2)) and in the range $1.5 \hat{\AA} \leq \mathrm{R}_{\mathrm{e}} \leq 9.6 \hat{\AA}$ (figs.(3-4))

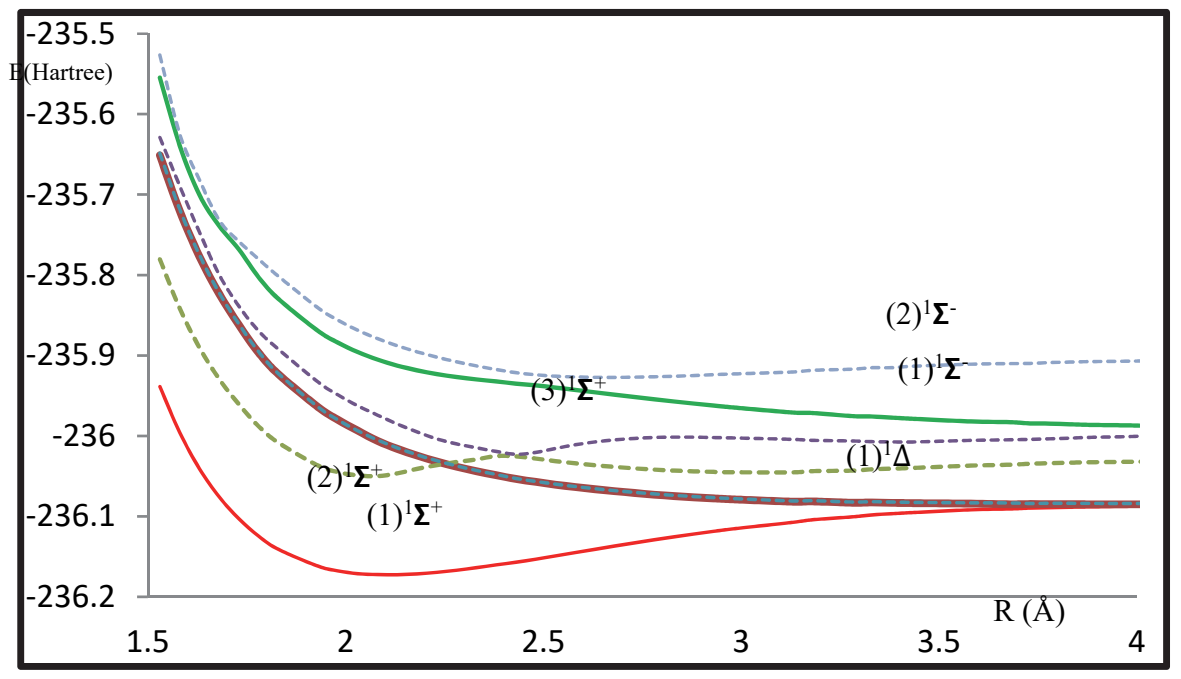

Figure 1. Potential Energy Curves of the ${ }^{1} \Sigma^{ \pm}$and ${ }^{1} \Delta$ States of the Molecule ZnS

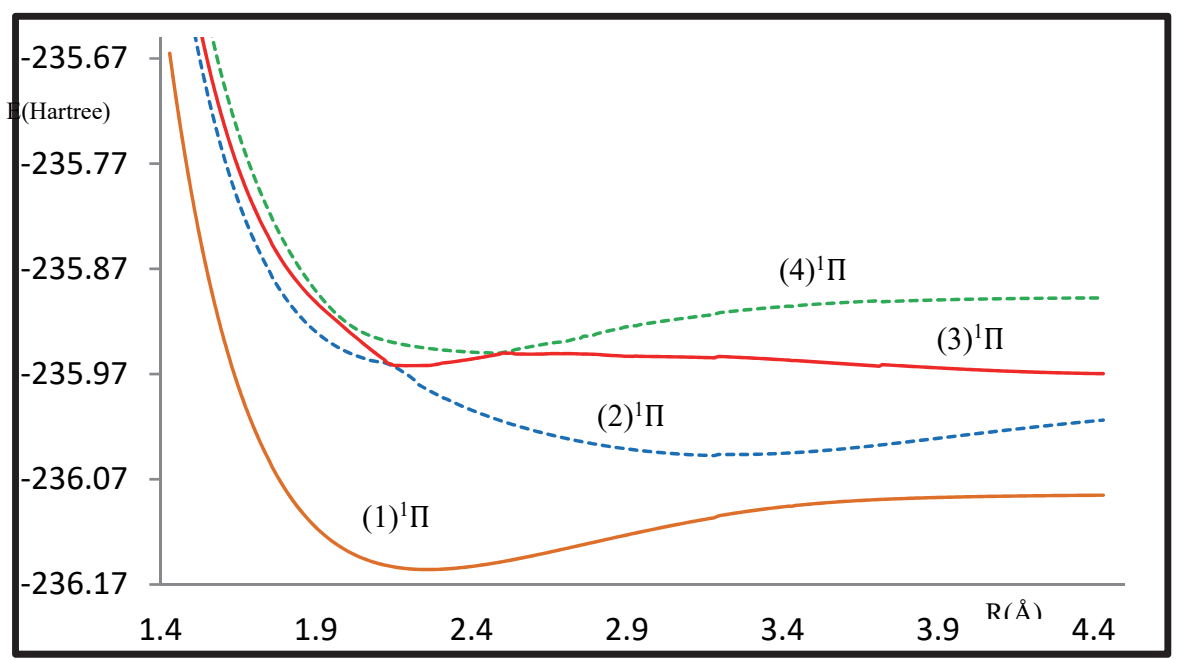

Figure 2. Potential Energy Curves of the ${ }^{1} \Pi$ States of the Molecule $\mathrm{ZnS}$ 


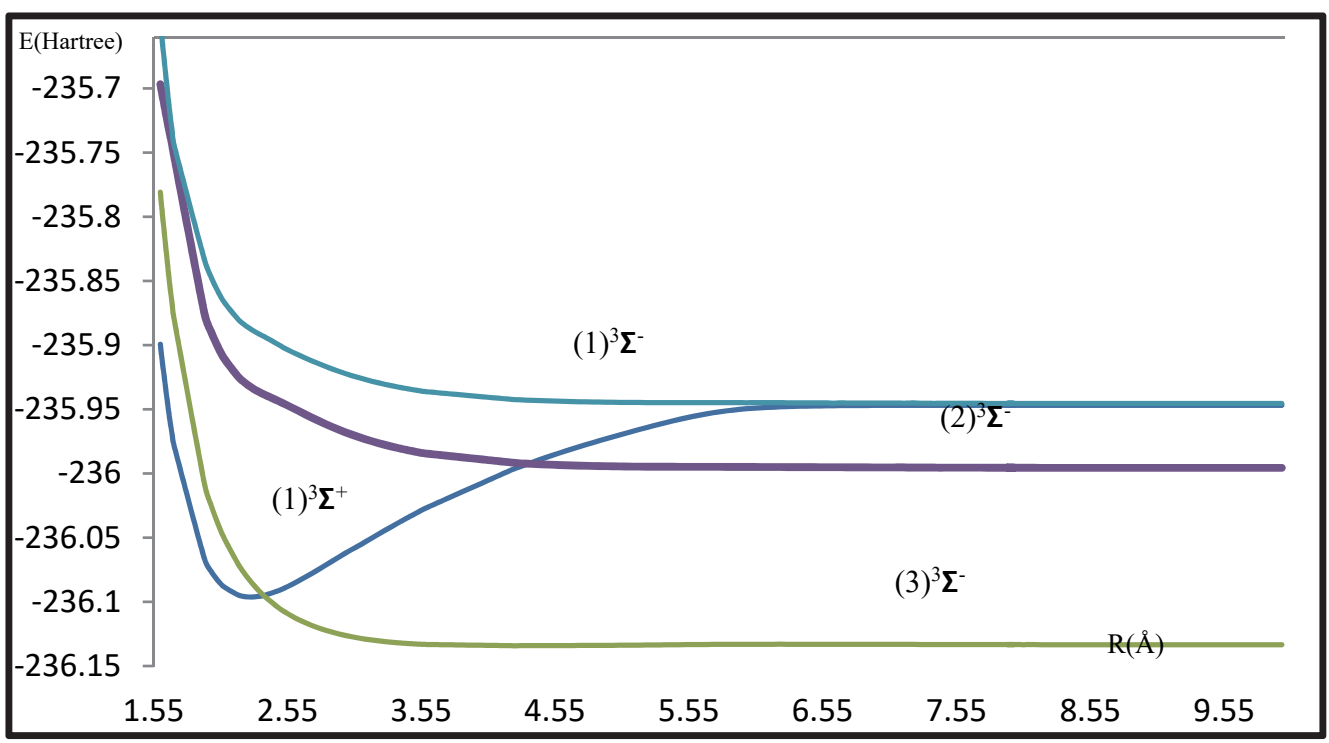

Figure 3. Potential Energy Curves of the ${ }^{3} \Sigma^{ \pm}$States of the Molecule ZnS

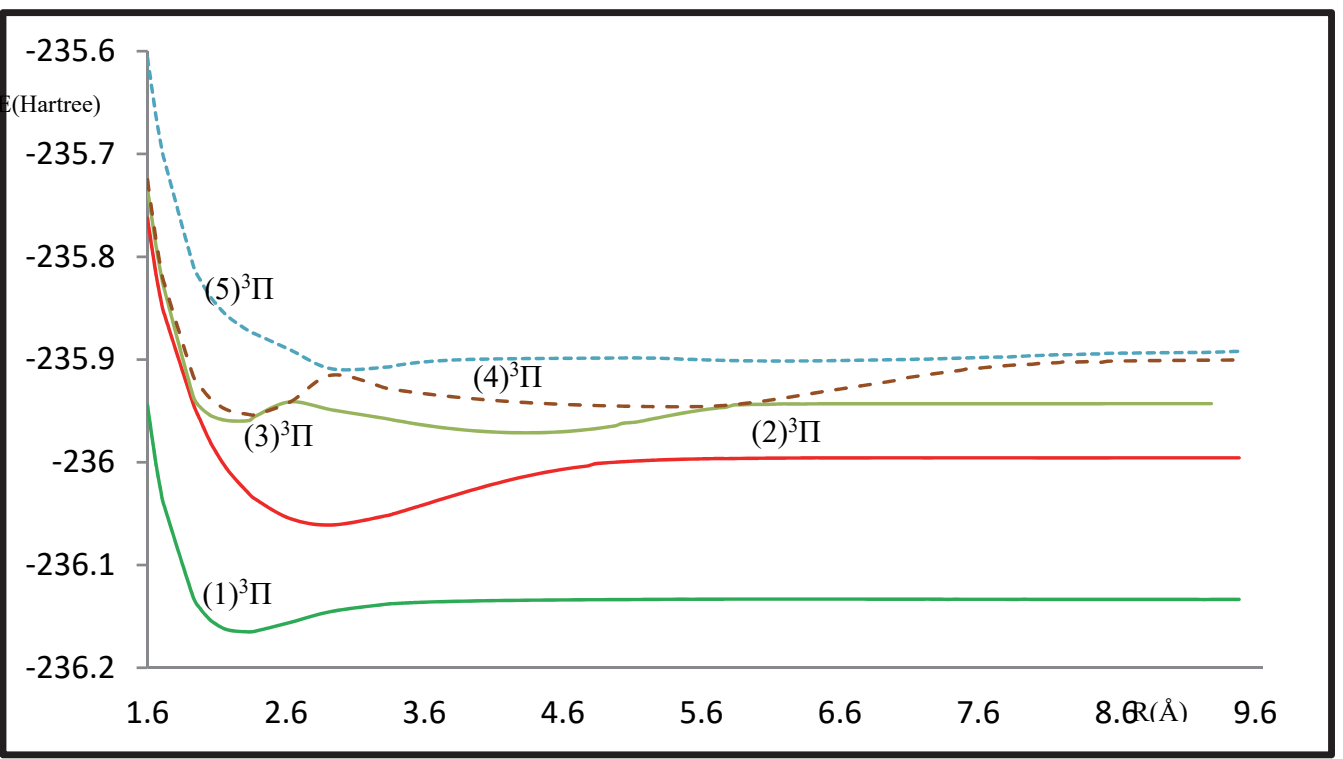

Figure 4. Potential Energy Curves of the ${ }^{3} \Pi$ States of the Molecule ZnS

The spectroscopic constants $\omega_{e}, T_{e}$, and $B_{e}$ have been obtained by calculating points around the internuclear distance at equilibrium $R_{e}$. Table 1 illustrates the spectroscopic constants for some lowest singlet and triplet electronic states of $\mathrm{ZnS}$ diatomic molecule. The obtained results are compared with other available studies (Peterson, Spheler, \& Singleton 2007), (Peterson, Spheler, \& Singleton 2007 -CCSD(T)), (Chamboud 2008), (Raptis, Papadopoulos, Sadlej, 1999), (Jensen, Roos, \& Ryde 2007), (Boldyrev, \& Simsons 1997), (Bauschlicher, \& Partridge .H 2001), (Dolg, Wedig, Stoll, \& Preuss, 1987), and (Kullie, Zhang, Kolb, \& Kolb, 2006).This comparison of the values is also shown in the given table. 
Table 1. The Spectroscopic Constant of Diatomic Molecule ZnS

\begin{tabular}{|c|c|c|c|c|c|c|c|c|}
\hline State & $\begin{array}{l}\mathrm{T}_{\mathrm{e}} \\
\mathrm{cm}^{-1}\end{array}$ & $\begin{array}{l}\Delta \mathrm{T}_{\mathrm{e}} / \mathrm{T}_{\mathrm{e}} \\
\%\end{array}$ & $\begin{array}{l}\mathrm{R}_{\mathrm{e}} \\
\AA \\
\end{array}$ & $\begin{array}{l}\Delta \mathrm{R}_{\mathrm{e}} / \mathrm{R}_{\mathrm{e}} \\
\%\end{array}$ & $\begin{array}{l}\begin{array}{l}\mathrm{B}_{\mathrm{e}} \\
\mathrm{cm}^{-1}\end{array} \\
\end{array}$ & $\begin{array}{l}\Delta \mathrm{B}_{\mathrm{e}} / \mathrm{B}_{\mathrm{e}} \\
\%\end{array}$ & $\begin{array}{l}\omega_{\mathrm{e}} \\
\mathrm{cm}^{-1}\end{array}$ & $\begin{array}{l}\Delta \omega_{\mathrm{e}} / \omega_{\mathrm{e}} \\
\%\end{array}$ \\
\hline $\mathrm{X}^{1} \Sigma^{+}$ & $\begin{array}{l}0.0^{\mathrm{a}} \\
0.0^{\mathrm{b}} \\
0.0^{\mathrm{c}} \\
0.0^{\mathrm{d}} \\
0.0^{\mathrm{e}} \\
0.0^{\mathrm{f}} \\
0.0^{\mathrm{g}} \\
0.0^{\mathrm{i}} \\
0.0^{\mathrm{j}} \\
0.0^{\mathrm{k}} \\
\end{array}$ & & $\begin{array}{l}2.106 \\
2.046 \\
3.886 \\
3.87 \\
3.92 \\
2.12 \\
3.91 \\
2.083 \\
2.048 \\
2.074\end{array}$ & $\begin{array}{l}2.93 \\
45.80 \\
45.58 \\
46.27 \\
0.66 \\
46.1 \\
1.10 \\
2.83 \\
1.54 \\
\end{array}$ & 0.1766 & & $\begin{array}{l}421.1 \\
459.4 \\
472.7 \\
447.0 \\
\\
\\
434.0 \\
478.0 \\
447.0 \\
\end{array}$ & $\begin{array}{l}8.33 \\
10.91 \\
5.79 \\
\\
\\
2.97 \\
11.90 \\
5.79 \\
\end{array}$ \\
\hline$(1)^{3} \Pi$ & $\begin{array}{l}1646.45^{\mathrm{a}} \\
3840.00^{\mathrm{b}} \\
3980.00^{\mathrm{c}} \\
2258.00^{\mathrm{g}} \\
1797.70^{\mathrm{i}} \\
2334.80^{\mathrm{j}} \\
1141.80^{\mathrm{k}} \\
2257.68^{\mathrm{l}}\end{array}$ & & $\begin{array}{l}2.29 \\
2.22 \\
2.23 \\
2.25 \\
2.30 \\
2.22 \\
2.25 \\
\end{array}$ & $\begin{array}{l}3.05 \\
2.69 \\
1.77 \\
0.43 \\
3.05 \\
1.77 \\
\end{array}$ & 0.1491 & & $\begin{array}{l}305.69 \\
343.8 \\
347.00 \\
329.00 \\
287.00 \\
349.00 \\
329.00\end{array}$ & $\begin{array}{l}11.08 \\
11.90 \\
7.08 \\
6.51 \\
12.40 \\
7.08 \\
\end{array}$ \\
\hline$(2)^{1} \Sigma^{-}$ & $3243.03^{\mathrm{a}}$ & & 2.17 & & 0.1656 & & 388.11 & \\
\hline$(1)^{1} \Pi$ & $\begin{array}{l}4464.00^{\mathrm{a}} \\
6888.00^{\mathrm{c}} \\
\end{array}$ & & $\begin{array}{l}4.27 \\
4.21 \\
\end{array}$ & 1.42 & 0.1656 & & $\begin{array}{r}351.82 \\
363.80 \\
\end{array}$ & 3.29 \\
\hline$(1)^{3} \Sigma^{+}$ & $\begin{array}{l}9375.03^{\mathrm{a}} \\
9696.36^{\mathrm{i}} \\
9864.47^{\mathrm{j}} \\
7462.84^{\mathrm{k}} \\
8798.25^{\mathrm{l}} \\
\end{array}$ & & $\begin{array}{l}4.70 \\
6.04 \\
4.52 \\
4.62\end{array}$ & $\begin{array}{l}22.18 \\
3.98 \\
1.73\end{array}$ & 0.3701 & & $\begin{array}{l}271.57 \\
7.00 \\
20.00 \\
18.00\end{array}$ & $\begin{array}{l}100 \\
100 \\
100\end{array}$ \\
\hline$(2)^{3} \Sigma^{+}$ & $\begin{array}{l}16778.1^{\mathrm{a}} \\
18539.4^{\mathrm{i}} \\
18340.7^{\mathrm{j}} \\
16937.4^{\mathrm{k}} \\
17899.3^{\mathrm{l}}\end{array}$ & & $\begin{array}{l}2.27 \\
2.25 \\
2.21 \\
2.22\end{array}$ & $\begin{array}{l}0.88 \\
2.71 \\
2.25\end{array}$ & 0.1517 & & $\begin{array}{l}324.68 \\
309.00 \\
336.00 \\
335.00\end{array}$ & $\begin{array}{l}5.07 \\
3.36 \\
3.08\end{array}$ \\
\hline$(2)^{3} \Pi$ & $24479.86^{2}$ & & 2.89 & & 0.9350 & & 226.53 & \\
\hline$(3)^{3} \Pi$ & $46551.32^{\mathrm{a}}$ & & 3.33 & & 0.7028 & & 705.09 & \\
\hline$(3)^{3} \Sigma$ & $52520.27^{a}$ & & 2.63 & & 0.1129 & & 221.19 & \\
\hline$(4)^{3} \Sigma$ & $54313.69^{a}$ & & 2.63 & & 0.1130 & & 207.91 & \\
\hline$(4)^{1} \Pi$ & $54509.71^{\mathrm{a}}$ & & 2.49 & & 0.1257 & & & \\
\hline$(2)^{1} \Delta$ & $64438.19^{\mathrm{a}}$ & & 2.55 & & 0.1199 & & 217.88 & \\
\hline
\end{tabular}

${ }^{(a)}$ Present Work, ${ }^{(b)}$ (Peterson, Spheler, \& Singleton, 2007), ${ }^{(c)}$ (Peterson, Spheler, \& Singleton, 2007 - CCSD(T)), ${ }^{(\mathrm{d})}$ (Chamboud 2008), ${ }^{(\mathrm{e})}$ (Raptis, Papadopoulos, \& Sadlej, 1999), ${ }^{\mathrm{f})}$ (Jensen, Roos, \& Ryde, 2007), ${ }^{(\mathrm{g})}$ (Boldyrev, \& Simsons, 1997), ${ }^{(\mathrm{i})}$ (Bauschlicher,\& Partridge, 2001), ${ }^{(\mathrm{j})}$ (Dolg, Wedig, Stoll, \& Preuss, 1987), ${ }^{\left({ }^{(}\right)}($Kullie, Zhang, Kolb, \& Kolb, 2006).

By examining the given data, you notice that ${ }^{1} \Sigma^{+}$is the lowest electronic state of the diatomic molecule $\mathrm{ZnS}$ followed by ${ }^{3} \Pi$ and ${ }^{1} \Pi$ respectively. These states are close to each other (Chamboud 2008). For ZnS molecule the three states, ${ }^{1} \mathrm{~S}^{+},{ }^{3} \mathrm{P}$ and ${ }^{3} \mathrm{~S}^{+}$have short bond lengths and high frequencies and therefore they are chemically bound, while the ${ }^{3} \mathrm{~S}^{-}$state is of long bond and very low vibrational frequency. The ${ }^{1} \Sigma^{+}$is known always as shorter equilibrium band energy dissociation and larger dipole moment compared to those of ${ }^{3} \Pi$ where state ${ }^{1} \Sigma^{+}$is stabilized relative to ${ }^{3} \Pi$ (Chamboud 2008). The ${ }^{1} \mathrm{~S}^{+}$state was concluded as ground electronic state with $\mathrm{r}_{\mathrm{e}}$ (the internuclear distance $)=2.106 \AA$ and $\mathrm{w}_{\mathrm{e}}$ (the harmonic frequency) $=421.15 \mathrm{~cm}^{-1}$ which are compatible with other studies performed before and acceptable with percentage $2.9 \%, 0.66 \%, 1.1 \%, 2.8 \%$, and $1.5 \%$ relative to some studies with respect to $r_{e}$. Similarly for $\omega_{e}$ it is compatible with some studies with percentage $2.9 \%, 5.7 \%, 7.1 \%$, and $8.3 \%$. And those the first exited state ${ }^{3} \mathrm{P}$ are calculated to be $\mathrm{r}_{\mathrm{e}}=2.29 \AA$ and $\mathrm{w}_{\mathrm{e}}=305.69 \mathrm{~cm}^{-1}$ which are also in agree with those obtained in previous studies with percentage $0.5 \%, 1.4 \%, 1.7 \%$, and $2.6 \%$ relative to $r_{e}$ and 
$6.5 \%$, and $7 \%$ with respect to $\omega_{\mathrm{e}}$. The sulfur atoms correlate in their ${ }^{3} \mathrm{P}$ ground electronic state with the ground electronic state of $\mathrm{Zn}$ to form ${ }^{3} \mathrm{~S}^{-}$states, not the singlet ${ }^{1} \mathrm{~S}^{+}$ground state. By comparing $\mathrm{r}_{\mathrm{e}}$ and $\omega_{\mathrm{e}}$ values $-4.27 \AA$ and $351.82 \mathrm{~cm}^{-1}$ respectively - of ${ }^{1} \Pi$ with values performed by other studies, the results are compatible by $1.4 \%$ and $3.2 \%$ respectively. In case of $(1)^{3} \Sigma^{-}, \mathrm{r}_{\mathrm{e}}$ shows compatibility with other studied by $1.5 \%$ and $3.9 \%$ while $\omega_{\mathrm{e}}$ shows a big difference with results of other studies, whereas the $(2)^{3} \Sigma^{-}$shows a good compatible with other studies by $0.75 \%, 1.9 \%$, and $2.4 \%$ for $\mathrm{r}_{\mathrm{e}}$ and $3 \%, 3.3 \%$, and $5 \%$ for $\omega_{\mathrm{e}}$. The other electronic states are not compared to the fact that they $\mathrm{r}$ studied for the first time. By proposing the comparison for $\mathrm{T}_{\mathrm{e}}$ we will see some compatible results with good percentage such that: ${ }^{3} \Pi$ agrees by $8.4 \%,(1)^{3} \Sigma^{-}$and $(2)^{3} \Sigma^{+}$agree with other results by $3.3 \%$ and $0.94 \%$ respectively. Other electronic states like ${ }^{1} \Pi$ show a big disagreement with the only result performed by $35 \%$ as well as ${ }^{3} \Pi$ which shows also a big disagreement with a mentioned study by $58 \%$. The rest of states are compared since as it was mentioned before are being studied for the first time. According to the rotational constant $\mathrm{B}_{\mathrm{e}}$, no comparison are done since it is not calculated by other studies. One can notice that our calculated values of the spectroscopic constants are in better agreement with experimental data then the theoretical values given in literature for these constants. With this agreement with literature values, we can predict the accuracy of the spectroscopic constants of the new electronic states investigated for the first time in the present work.

\subsection{Static Dipole Moment}

By taking the $\mathrm{Zn}$ atom at the origin and sulfur atom along the internuclear Z-axis, we present in Figs (5-6-7-8) the calculated values of the static dipole moment in term of the internuclear distance $R$.

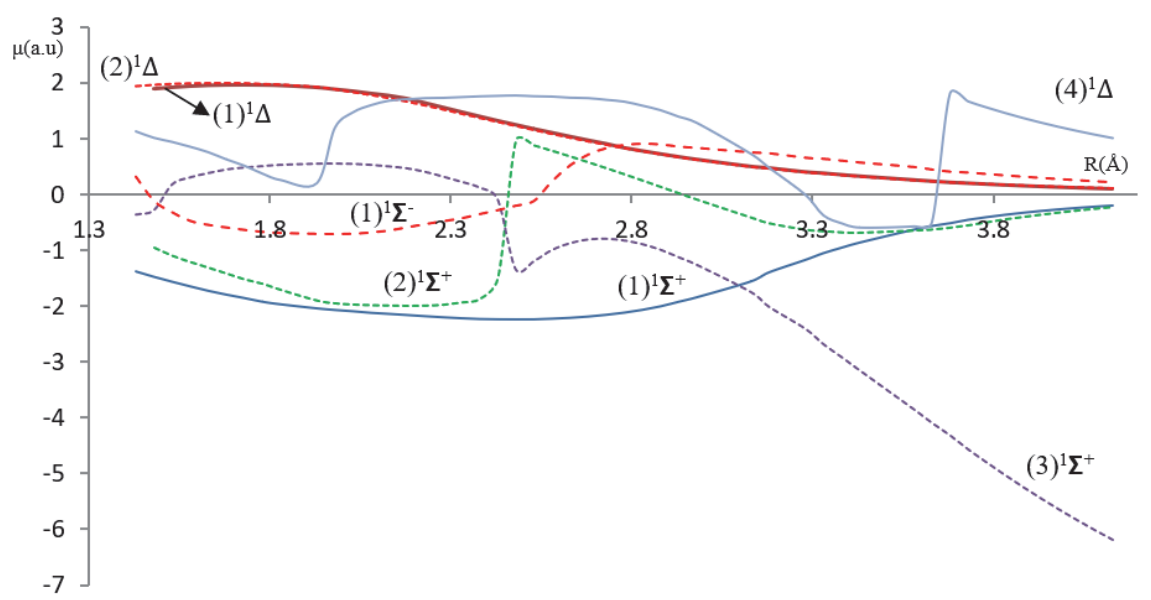

Figure 5. Static Dipole Curves of the Electronic States ${ }^{1} \Sigma^{ \pm}$, and ${ }^{1} \Delta$ of the Molecule ZnS

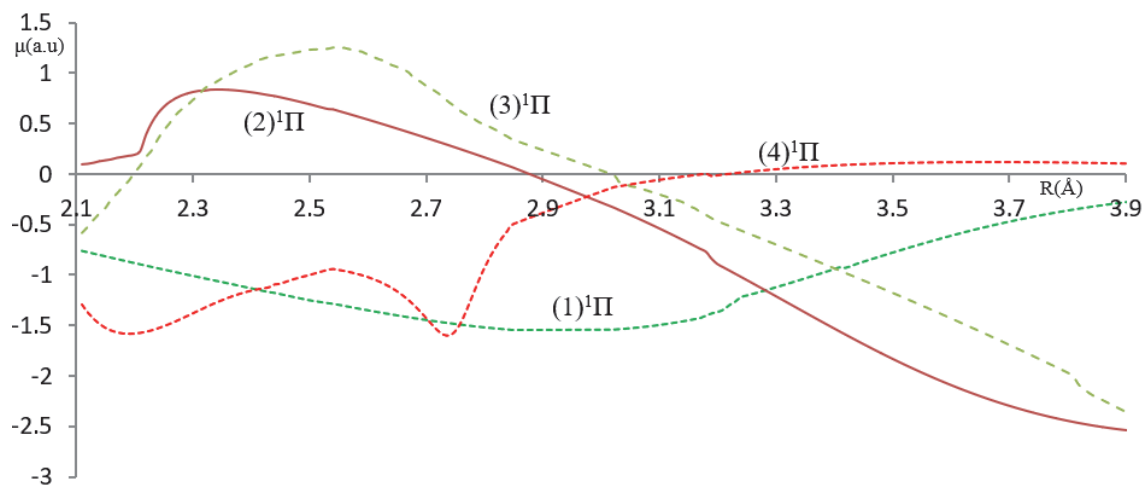

Figure 6. Static Dipole Curves of the Electronic States ${ }^{1} \angle$ of the Molecule ZnS 


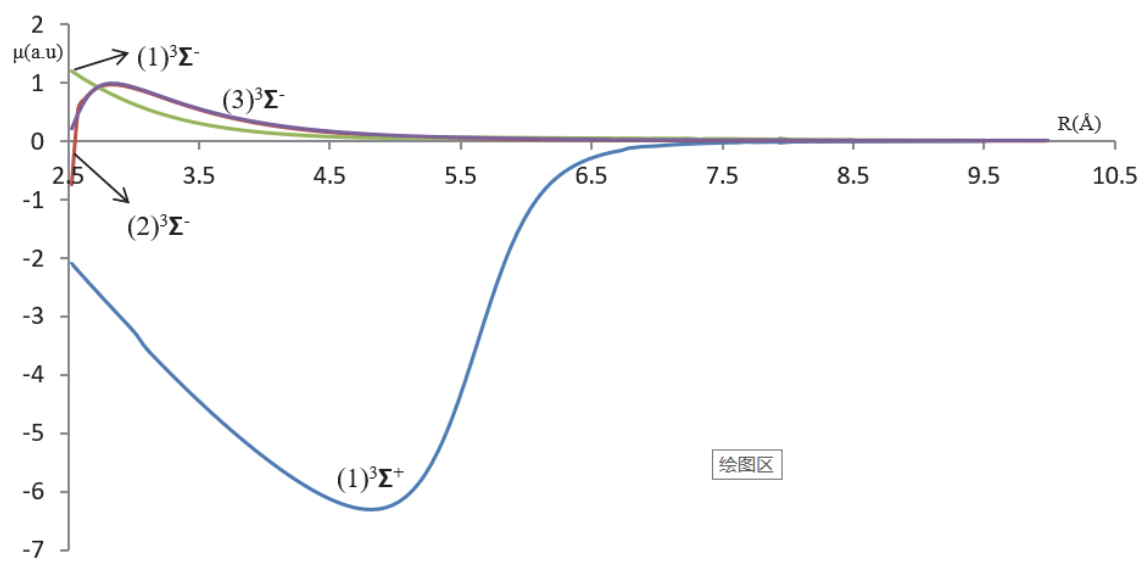

Figure 7. Static Dipole Curves of the Electronic States ${ }^{3} \Sigma^{ \pm}$of the Molecule ZnS.

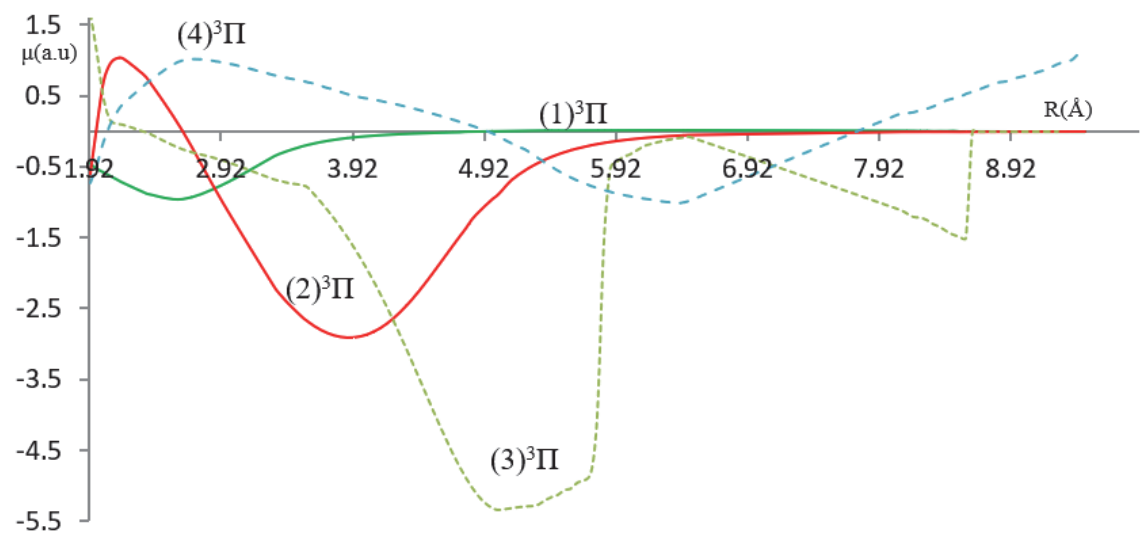

Figure 8. Static Dipole Curves of the Electronic States ${ }^{3} \Pi$ of the Molecule ZnS.

The dipole value of the ${ }^{1} \mathrm{~S}^{+}$state is much higher than that of the two P states, which lie somehow above that of the ${ }^{3} \mathrm{~S}^{-}$state. Except for the dipole moment of the ${ }^{1} \mathrm{P}$ state, these values vary little with the inter-atomic distance (Chamboud 2008). The investigation of these curves is mainly used to discuss the bond nature, the polarity of the states and their interactions. As the internuclear distance increases one can notice three types of the DMC's for the singlet, triplet and quintet electronic states: curves in the positive region which are corresponding to an ionic structure of $\mathrm{Zn}^{\delta-} \mathrm{S}^{\delta+}$ type, curves in the negative region which are corresponding to an ionic structure of $\mathrm{Zn}^{\mathrm{d}+} \mathrm{S}^{\mathrm{d}-}$ type, and curves passing from one region to another by changing the ionic structure. It is noticed that at large internuclear distances, the dipole moment curves of all the investigated electronic states tend smoothly to zero which is theoretically the correct behavior for a molecule that dissociates into natural fragments. The sharp change in the directions of the DM curves indicate an avoided crossing of the potential energy curves at the same position of the internuclear distance where the polarity of the atoms is reversed (Atkins \& Friedman). From this agreement, we can confirm the validity and the accuracy of the calculation of the studied excited electronic states.

It is known that the canonical functions approach can replace the radial Schrödinger equation (Kobeissi, Korek, \& Dagher 1989), and (Korek 1999) where the eigenvalues $E_{v}$, and the rotational constants $B_{v}$ have been calculated for the electronic states $(1)^{3} \mathrm{P}$ and $(1)^{3} \mathrm{~S}^{+}$. These values are given in Table 2 .

Table 2. The Eigenvalue $E_{v}$, and the Rotational Constant $B_{v}$ of the Molecule $\mathrm{ZnS}$.

\begin{tabular}{l|l|l|l} 
State & $\mathrm{V}$ & $\mathrm{E}_{\mathrm{v}}\left(\mathrm{cm}^{-1}\right)$ & $\mathrm{B}_{\mathrm{v}} \times 10^{2}\left(\mathrm{~cm}^{-1}\right)$ \\
\hline & & & \\
\hline & 0 & 164 & 16.77 \\
\cline { 2 - 4 } & 1 & 489 & 16.536 \\
\hline
\end{tabular}




\begin{tabular}{|c|c|c|c|}
\hline \multirow{25}{*}{$(1)^{3} \Pi$} & 2 & 809 & 16.388 \\
\hline & 3 & 1124 & 16.249 \\
\hline & 4 & 1433 & 16.104 \\
\hline & 5 & 1737 & 15.981 \\
\hline & 6 & 2035 & 15.943 \\
\hline & 7 & 2326 & 16.137 \\
\hline & 8 & 2612 & 16.617 \\
\hline & 9 & 2890 & 15.279 \\
\hline & 10 & 3162 & 15.1 \\
\hline & 11 & 3427 & 14.915 \\
\hline & 12 & 3685 & 14.724 \\
\hline & 13 & 3936 & 14.53 \\
\hline & 14 & 4179 & 14.356 \\
\hline & 15 & 4415 & 14.288 \\
\hline & 16 & 4641 & 14.499 \\
\hline & 17 & 4858 & 15.006 \\
\hline & 18 & 5066 & 15.309 \\
\hline & 19 & 5262 & 9.359 \\
\hline & 20 & 5448 & 23.647 \\
\hline & 21 & 5623 & 10.533 \\
\hline & 22 & 5786 & 160.918 \\
\hline & 23 & 5937 & 13.705 \\
\hline & 24 & 6075 & 6.388 \\
\hline & 25 & 6200 & 32.162 \\
\hline & 26 & 6313 & 14.111 \\
\hline \multirow{29}{*}{$(1)^{3} \boldsymbol{\Sigma}^{+}$} & 0 & 177 & 16.8872 \\
\hline & 1 & 519 & 16.8051 \\
\hline & 2 & 854 & 16.6824 \\
\hline & 3 & 1190 & 16.6229 \\
\hline & 4 & 1519 & 16.5143 \\
\hline & 5 & 1848 & 16.4259 \\
\hline & 6 & 2174 & 16.3458 \\
\hline & 7 & 2499 & 16.2474 \\
\hline & 8 & 2821 & 16.1613 \\
\hline & 9 & 3140 & 16.0593 \\
\hline & 10 & 3457 & 15.9611 \\
\hline & 11 & 3771 & 15.8657 \\
\hline & 12 & 4082 & 15.7654 \\
\hline & 13 & 4391 & 15.6692 \\
\hline & 14 & 4698 & 15.5691 \\
\hline & 15 & 5003 & 15.4653 \\
\hline & 16 & 5305 & 15.362 \\
\hline & 17 & 5605 & 15.2522 \\
\hline & 18 & 5903 & 15.1344 \\
\hline & 19 & 6199 & 15.0078 \\
\hline & 20 & 6492 & 14.8649 \\
\hline & 21 & 6784 & 14.7024 \\
\hline & 22 & 7073 & 14.5212 \\
\hline & 23 & 7359 & 14.3194 \\
\hline & 24 & 7643 & 14.0992 \\
\hline & 25 & 7924 & 13.8691 \\
\hline & 26 & 8202 & 13.6377 \\
\hline & 27 & 8476 & 13.4175 \\
\hline & 28 & 8746 & 13.2303 \\
\hline
\end{tabular}




\begin{tabular}{|l|l|l}
\hline 29 & 9014 & 13.0954 \\
\hline 30 & 9281 & 13.0085 \\
\hline 31 & 9546 & 12.9417 \\
\hline 32 & 9811 & 12.8689 \\
\hline 33 & 10074 & 12.7819 \\
\hline 34 & 10335 & 12.6821 \\
\hline 35 & 10594 & 12.5678 \\
\hline 36 & 10851 & 12.4377 \\
\hline 37 & 11107 & 12.299 \\
\hline 38 & 11361 & 12.1639 \\
\hline 39 & 11613 & 12.0434 \\
\hline 40 & 11864 & 11.9426 \\
\hline 41 & 12112 & 11.8597 \\
\hline 42 & 12359 & 11.7867 \\
\hline 43 & 12604 & 11.7147 \\
\hline 44 & 12848 & 11.6352 \\
\hline 45 & 13089 & 11.543 \\
\hline 46 & 13329 & 11.438 \\
\hline 47 & 13568 & 11.326 \\
\hline 48 & 13804 & 11.215 \\
\hline 49 & 14039 & 11.1131 \\
\hline 50 & 14272 & 11.024 \\
\hline 51 & 14504 & 10.9482 \\
\hline 52 & 14733 & 10.8808 \\
\hline 53 & 14962 & 27.4959 \\
\hline 54 & 15188 & 10.7447 \\
\hline 55 & 15413 & 9.9711 \\
\hline 56 & 15636 & 74.6 \\
\hline 57 & 15858 & 26.3 \\
\hline
\end{tabular}

To draw connections among the different investigated data, we will refer to the following spectroscopic formulas (Herzberg 1950)

$$
\begin{gathered}
\mathrm{E}_{\mathrm{v}}=\omega_{\mathrm{e}}(\mathrm{v}+1 / 2)-\omega_{\mathrm{eXe}}(\mathrm{v}+1 / 2) 2+. . \\
\mathrm{B}_{\mathrm{v}}=\mathrm{Be}_{\mathrm{e}}-\alpha(\mathrm{v}+1 / 2) . .
\end{gathered}
$$

For $\mathbf{v}=0$ of the electronic states $(1)^{3} \Pi$ and (1) ${ }^{3} \Sigma^{+}$, with approximation to the first term, implies that $\omega_{\mathrm{e}}=328$ $\mathrm{cm}^{-1}$ is a constant whose value is in good accordance to $\omega_{\mathrm{e}}=312 \mathrm{~cm}^{-1}$, and $\omega_{\mathrm{e}}=354 \mathrm{~cm}^{-1}$ is close to $\omega_{\mathrm{e}}=340 \mathrm{~cm}^{-1}$ respectively. Also, the value of $B_{e}=0.1682 \mathrm{~cm}^{-1}$ is close to the value of $B_{e}=0.1491 \mathrm{~cm}^{-1}$, and $B_{e}=0.1679 \mathrm{~cm}^{-1}$ is close to $B_{e}=0.1493 \mathrm{~cm}^{-1}$ respectively. No comparison with other data since they given here for the first time.

\section{Conclusion}

The ab-initio MRCI $+\mathrm{Q}$ calculation of permanent dipole moment and the potential energy curves was investigated for 21 singlets, and triplet electronic states for diatomic molecule zinc sulfide $\mathrm{ZnS}$. The study includes plots of these curves, and the spectroscopic constants $\mathrm{R}_{\mathrm{e}}, \omega_{\mathrm{e}}, \mathrm{T}_{\mathrm{e}}$, and $\mathrm{B}_{\mathrm{e}}$ of the investigated electronic states which are compared with the results of other studies when available. The spectroscopic constants for 7 states are given here for the first time. The confirmation of these theoretical investigated data can be done by a future experiment for these electronic states of the molecule $\mathrm{ZnS}$.

\section{References}

Allouche A. R. (2011). Gabedit: A graphical user interface for computational chemistry software. J. Comp.Chem., 32, 174-182. https://doi.org/10.1002/jcc. 21600

Atkins, P., \& Friedman, R. (2016). Molecular Quantum Mechanics, Fourth Edition, Oxford University PRESS. Retrieved from https://www.oxfordtextbooks.co.uk/orc/mqm5c/

Herzberg. G., Molecular, S., \& Molecular, S. (1950). Spectra of Diatomic Molecules, D. Van Nostrand Company, Inc., New Jersey, New York, London, Toronto. https://doi.org/ISBN 0-12-245606-8. 
Kobeissi, H., Korek, M., \& Dagher, M. (1989). On the computation of diatomic centrifugal distortion constants: Exact solution for initial value problems. J. Mol. Spectrosc., 138, 1-4, 1989. https://doi.org/10.1016/0022-2852(89)90092-1U

Mahmoud K. (1999). Highly Accurate diatomic Centrifugal Distortion Constants. Comput. Phys., 119, 169. https://doi.org/10.1002/jcc.540130909

MOLPRO. (2015). Retrieved from https://www.molpro.net/info/2015.1/doc/update/node1.html

Peterson, K. A., Spheler, B. C., Singleton, J. M., \& Mol, P. (2007) 1139 using MRCI+Q/CBS. https://doi.org/10.1080/00268970701241664

Pr. Chamboud Gilberte theoretical study of electronic structure and spectroscopy of molecules containing metallic atoms 2008, thèse dirigèe. Retrieved from https://tel.archives-ouvertes.fr/tel-00462184

Wu, H. Z., Qiu, D. J., Cai, Y. J., Xu, L. X., Chen, W. B., \& Cryst, J. G. (2002), 245-50. https://doi.org/10.1021/ct700205n

Zinc Sulfide (N/A). Retrieved from https://en.m.wikipedia.org/wiki/Zinc_Sulfide

\section{Copyrights}

Copyright for this article is retained by the author(s), with first publication rights granted to the journal.

This is an open-access article distributed under the terms and conditions of the Creative Commons Attribution license (http://creativecommons.org/licenses/by/4.0/). 